Conclusions These findings are reassuring. Lower risks in some comparisons may reflect chance or a degree of health selection out of hazardous work. In any event, current employment practices are not placing diabetic workers at particular risk of workplace injury.

\section{MULTIPLE JOBS AND INCREASED RISK OF INJURY: FINDINGS FROM THE NATIONAL HEALTH INTERVIEW SURVEY}

H M W Marucci-Wellman, Willetts, Lin, Brennan, Verma. The Liberty Mutual Research Institute for Safety, Hopkinton, United States of America

\subsection{6/oemed-2013-101717.301}

Objectives Approximately 5-10\% of US jobholders report working multiple jobs within the same week, and up to $20 \%$ have reported working in more than one job within a year. However, occupational injury surveillance research has largely explored only exposures at the primary job or the job in which the injury occurred. The objective of this study was to compare the risk of injury for those working in multiple jobs $(\mathrm{MJH})$ with those working in only one job (SJH).

Methods The National Health Interview Survey is the only national survey to collect information annually about selfreported injuries in the last 3 months information about working multiple jobs. Using information for years 1997-2011, we calculated the rate of multiple job holding in the US and compared characteristics and risk of injury (work and non-work) with those who worked in only one job.

Results The risk of work and non-work injury was higher for MJHs compared with SJHs (9.9 vs. 7.4 non-work injuries per 100 workers, and 4.2 vs. 3.3 work injuries per 100 workers) and the rate of injury remained higher after controlling for work hours $(\mathrm{p}<1)$. There was a significant elevated risk of injury for some subgroups (e.g. young workers aged 18-24 who worked in multiple jobs had a risk of injury, both during outside of work, of 19 per 100 workers, almost $40 \%$ higher than their SJH counterparts).

Conclusions Our findings suggest that multiple job holding is associated with an increased risk of injuries (work and nonwork) and must be considered in injury surveillance. Suggested pathways exist for $\mathrm{MJH}$ to increase the risk of injury: fatigue, inexperience in jobs, hurried behaviour, or additional biological/ emotional stress from alternating between different types of exposure.

\section{PREDICTING RISK OF LOST WORK-TIME INJURY IN SMALL CONSTRUCTION COMPANIES}

${ }^{1} \mathrm{~K}$ S Schofield, ${ }^{2}$ Alexander, ${ }^{2}$ Goodwin Gerberich, ${ }^{2}$ Ryan, ${ }^{2}$ MacLehose. ${ }^{1}$ SFM/University of Minnesota, Minneapolis, United States of America; ${ }^{2}$ University of Minnesota, Minneapolis, United States of America

\subsection{6/oemed-2013-101717.302}

Objective The construction industry experiences a high rate of injuries. A pattern of minor injuries may increase risk of severe injuries within a company. The assistance of outside safety and health professionals (S\&HP) may help reduce risk of injury in construction firms. The goal of this study was to determine the association between minor injuries and risk of lost-time injury and to determine the association between company contact with an external S\&HP and risk of lost-time injury.
Methods Workers' compensation data were evaluated covering 1,360 construction companies from 2004-2009. In analysis 1 , minor injury experience prior to lost-time injury was categorised as: $0-1$ claim, 2-3 claims, 4-6 claims, 7 or more claims. For analysis 2, S\&HP contact prior to lost-time injury was categorised as: 0 contacts, 1 contact, 2 contacts, and 3 or more contacts. Hazard Ratios (HR) and 95\% confidence intervals (CI) were estimated using a proportional hazards regression model and accounting for repeated events and time-varying covariates. A model based variance estimate accounted for correlated observations within companies over time. Models included confounding covariates of company size and union status.

Results Compared to experiencing 0-1 claims, increased risk occurred with experiencing $2-3$ claims $(\mathrm{HR}=1.25$, CI $=1.32$ 1.75), 4-6 claims $(\mathrm{HR}=1.36, \mathrm{CI}=1.19-1.56)$, and 7 or more claims $(\mathrm{HR}=1.52, \mathrm{CI}=1.12-1.39)$. Compared to experiencing no S\&HP contact, reduced risk occurred with experiencing 1 contact $(\mathrm{HR}=0.77, \mathrm{CI}=0.67-0.88)$ and 2 contacts $(\mathrm{HR}=$ $0.63, \mathrm{CI}=0.55-0.74)$. Once companies reached the highest category of contacts, three or more, there was no longer and significant reduction in risk $(\mathrm{HR}=1.06, \mathrm{CI}=0.92-1.22)$. Companies of larger size were associated with greater risk of a lost-time claim, as were union companies.

Conclusion The results indicate increasing non-lost-time claims experience is associated with increasing risk of lost-time injury, whereas contact of a S\&HP may reduce the risk of lost-time injury.

\section{ELEVATED RISK OF PSYCHIATRIC DISORDERS AFTER OCCUPATIONAL INJURY}

${ }^{1} \mathrm{~L}$ Guo, ${ }^{2} \mathrm{Lin},{ }^{3} \mathrm{Chu},{ }^{4} \mathrm{Kuo},{ }^{5} \mathrm{Wu},{ }^{2} \mathrm{H}$ wang. ${ }^{1}$ National Taiwan University, Taipei, Taiwan; ${ }^{2}$ National Taiwan University/Occupational Medicine and Industrial Hygiene, Taipei, Taiwan; ${ }^{3}$ National Taiwan University/Environmental and Occupational Medicine, Taipei, Taiwan; ${ }^{4}$ Chung-Shan Medical University/Department of Psychiatry, Taichung, Taiwan; ${ }^{5}$ National Yang-Ming University/Institute of Health and Welfare Policy, Taipei, Taiwan

\subsection{6/oemed-2013-101717.303}

Objectives Psychiatric conditions are known to occur after traumatic injuries. This study aimed to determine the incidence rates of psychiatric disorders within one year after occupational injury and to compare the incidence of psychiatric disorders among people sustaining occupational and non-occupational injuries, and the enrollees of the National Health Insurance (NHI) without injury.

Methods We used cohort approach in this investigation. All eligible subjects were insured by the NHI of Taiwan, and aged 18 65 years old. We identified enrollees who sustained occupational injury and non-occupational injuries in 2001. Those in the reference group were patients who ever used the NHI for any medical condition in 2001. The patients who had been treated due to any injury within one year before and after the target injury/condition in 2001 and who had been treated due to psychiatric disorders within one year before the date of target injury/condition were excluded.

Results A total of 563,461 patients were enrolled in this study. Among them, 1060 patients sustained occupational injury, 7442 patients sustained non-occupational injury, 554,959 patients ever used NHI for any medical condition in 2001. The incidence rates of any psychiatric disorders within one year after occupational injury requiring hospitalisation, occupational injury treated as outpatient, non-occupational injury requiring hospitalisation, non-occupational injury treated as outpatient, 